\title{
Physical illnesses in psychiatric and general population A network analysis
}

Ivona Šimunović Filipčić ${ }^{1}$, Žarko Bajić ${ }^{2}$, Marina Šagud ${ }^{1,3}$, Igor Filipčić2,3,4

${ }^{1}$ Department of Psychiatry and Psychological Medicine, University Hospital Center Zagreb, Zagreb, Croatia; ${ }^{2}$ Psychiatric Hospital "Sveti Ivan", Zagreb, Croatia; ${ }^{3}$ School of Medicine, University of Zagreb, Zagreb, Croatia; ${ }^{4}$ Faculty of Dental Medicine and Health, Josip Juraj Strossmayer University of Osijek, Osijek, Croatia

OBJECTIVE: The authors examined the differences in the networks of self-reported chronic physical illnesses $(\mathrm{CPI})$ in psychiatric patients $(\mathrm{PP})$ and the general population (GEP).

BACKGROUND: Converging evidence suggests that PP have a higher prevalence of $\mathrm{CPI}$ and multimorbidity than the GEP. However, there is the evidence-based knowledge gap between multimorbidities and different, prevalent, single CPI, and is partially caused by the complexity of the proper analysis.

MATERIALS AND METHODS: We utilized data from two large samples, one from the population of PP $(n=926)$, and the other from the GEP $(n=584)$. We performed the network analysis of 12 self-reported $\mathrm{CPI}$, and the network comparison test to analyze the particular CPI impact on the networks strength and structure.

\begin{tabular}{|c|c|c|}
\hline & $\begin{array}{c}\text { General } \\
\text { population } \\
(\mathrm{n}=584)\end{array}$ & $\begin{array}{c}\text { Psychiatric } \\
\text { patients } \\
(\mathrm{n}=926)\end{array}$ \\
\hline \multicolumn{3}{|l|}{ Gender } \\
\hline male & $271(46.4)$ & $497(53.7)$ \\
\hline female & $313(53.6)$ & $429(46.3)$ \\
\hline Age (years), median (IQR) & $45(32-55)$ & $46(35-55)$ \\
\hline Any non-psychiatric medication used during the last two weeks & $247(42.4)$ & $418(46.8)$ \\
\hline \multicolumn{3}{|l|}{$\begin{array}{l}\text { Psychiatric patients } \\
\text { Psychiatric disorder* }\end{array}$} \\
\hline Schizophrenia, schizotypal and delusional disorders (F20-F29) & & $327(36.2)$ \\
\hline Mood (affective) disorders (F30-F39) & & $305(33.8)$ \\
\hline Neurotic, stress-related and somatoform disorders (F40-F48) & & 288 (31.9) \\
\hline Disorders of adult personality and behavior (F60-F69) & & $232(25.7)$ \\
\hline $\begin{array}{l}\text { Mental and behavioral disorders due to psychoactive } \\
\text { substance use (F10-F19) }\end{array}$ & & $190(21.0)$ \\
\hline Organic, including symptomatic, mental disorders (F00-F09) & & $74(8.2)$ \\
\hline $\begin{array}{l}\text { Behavioral syndromes associated with } \\
\text { psychological disturbances and physical factors (F50-F59) }\end{array}$ & & $33(3.7)$ \\
\hline Other & & $33(3.7)$ \\
\hline \multicolumn{3}{|l|}{ Number of psychiatric disorders } \\
\hline one & & $431(46.5)$ \\
\hline two & & $315(34.0)$ \\
\hline three or more & & $180(19.4)$ \\
\hline Previous psychiatric hospitalizations, median (IQR) & & $2(0-5)$ \\
\hline \multirow{2}{*}{\multicolumn{3}{|c|}{ Medication }} \\
\hline & & \\
\hline antipsychotics & & $519(56.0)$ \\
\hline $1^{\mathrm{st}}$ generation & & $176(19.3)$ \\
\hline $2^{\text {nd }}$ generation & & $411(45.1)$ \\
\hline clozapine & & $69(7.6)$ \\
\hline antidepressants & & $557(60.2)$ \\
\hline SSRI & & $320(34.6)$ \\
\hline SNRI & & $126(13.6)$ \\
\hline NaSSA & & $66(7.1)$ \\
\hline other antidepressants & & $47(5.1)$ \\
\hline benzodiazepines & & $758(81.9)$ \\
\hline
\end{tabular}

Data are presented as number (percentage) of participants if not stated otherwise. Abbreviation: IQR= interquartile range. Data were missing on education for $3(0.5 \%)$ of participants from the general population and for $2(0.2)$ of psychiatric patients; on marital status for $4(0.7 \%)$ of participants from the general population and for $10(1.1 \%)$ of psychiatric patients; on non-psychiatric medication for $2(0.3 \%)$ participants from the general population and $33(3.6 \%)$ of psychiatric patients; for psychiatric diagnosis in 23 (2.5\%) of participants. ${ }^{*}$ Total exceeds $100 \%$ because of psychiatric comorbidities
Results: Two groups were comparable regarding the age and the use of non-psychiatric medication. The prevalence of any $\mathrm{CPI}$ was significantly higher in PP $(R R=1.36$; Cl95\% 1.23-1.50). However, the global strength and structure of the CPI networks in the two populations were not significantly different $(p=0.190$, $p=0.140$, respectively). Considering all three centrality indices, the most central $\mathrm{CPI}$ in both population was hypertension.

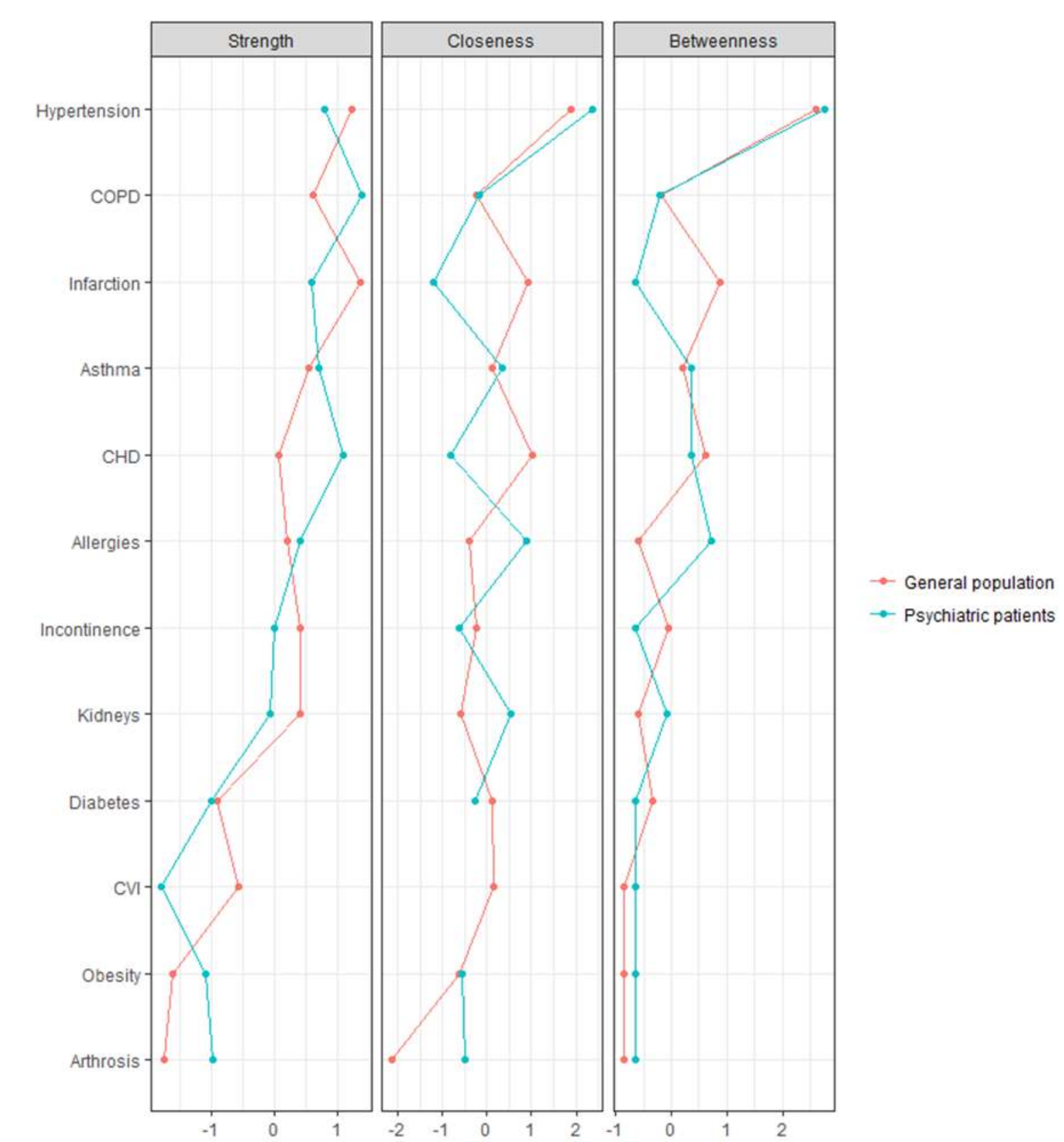

CONCLUSIONS: The global strength and structure of CPI networks are not significantly different between PP and GEP, indicating that the causal mechanisms of specific multimorbidity patterns may be similar in both population. Organized and accessible somatic medicine integrated into the psychiatric treatment may be a pillar to improve the physical health in the psychiatric population. Further, interventions focusing on prevention, early recognition, and treatment of hypertension represent priority. 